\title{
Experimental and Numerical Investigation for Mechanical Ventilated Greenhouse (Comparison between Different Turbulence Models)
}

\author{
Ahmed E. Newir \\ Mechatronics Engineering Department, \\ Faculty of Engineering, October 6 University, Egypt \\ Mohamed A. Ibrahim \\ Mechatronics Engineering Department, \\ Faculty of Engineering, October 6 University, Egypt
}

\begin{abstract}
Using computational fluid dynamics (CFD) in agriculture field especially in designing greenhouses is becoming ever more important to reduce the energy consumption, wherefore a comparison between the experimental and numerical results increasing the credibility of theoretical studies and therefore depending on it. Forced ventilation greenhouse has been used in even span greenhouse to study the experimental measurements of temperature distribution in summer rush hours, the experiment has been performed in October 6 University, Giza, Egypt. More than one turbulence models (Standard K- $\varepsilon$, RNG K- $\varepsilon$, Reynolds Stress Model (RSM), Transition Shear-Stress Transport (SST), Standard K- $\omega$ and $\mathrm{K}-\mathrm{KL}-\omega$ ) are used for the (CFD) numerical study implemented for comparison between the experimental and numerical measurements. After this study can get that SST turbulence model is the most efficient numerical solution for this case, a good qualitative and quantitative agreement found between the numerical results and the experimental measurements.
\end{abstract}

Keywords: Greenhouse; Mechanical ventilation; CFD.

\section{Introduction}

Operating mechanical ventilation effects on the yield and quality of almost all greenhouse crops. Mechanical ventilation is used to reduce the greenhouse effect inside the greenhouse during the hot days, which leads to attain the optimum crops temperature with minimum power. The numerical solution allows to make changes to the geometrical shape and method of mechanical ventilation by computational fluid 
dynamics (CFD) to reach the ideal solution for mechanical ventilation which provides better efficiency.

The first user for an early version of a CFD model to predict the distributions of climatic factors inside and outside small naturally ventilated greenhouses is Okushima (Okushima, Sase, \& Nara, 1989). Two equation K- $\epsilon$ model is used to computed air flow distributions compared with the wind-tunnel results of S. Sase et al. (Sase \& Takakura, 1984), which made different openings in the roof and side walls. While the experimental results showed little correlation with the computational model, the study demonstrated the possibility of using a CFD model to predict environmental distributions for naturally ventilated greenhouses.

I. B. Lee and T. H. Short (Lee \& Short, 2000) studied two-dimensional K- $\epsilon$ model to validate the experimental data for multi-span greenhouse in different velocity inlet at $0.9 \mathrm{~m} / \mathrm{s}$ and $2.5 \mathrm{~m} / \mathrm{s}$, validation made with only four air temperatures sensors across the $33 \mathrm{~m} * 35 \mathrm{~m}$ multi-span greenhouse, which means a simple understanding of temperature distribution in the greenhouse. The maximum error between the experimental measurements and numerical data was 3.2\%.

Campen et al. (Campen \& Bot, 2003) show that the three-dimensional calculations are preferable over the two-dimensional calculations, for computational assessment of ventilation rate with wind direction. Crop not considered in the model since no crop grown during the experiments. The calculations resembled experimental data within $15 \%$. The wind speed correlated linearly with ventilation rate for both configurations without the buoyancy effect, which goes with the basic theory on ventilation. The CFD calculations used the standard $\mathrm{K}-\epsilon$ model and indicated that ventilation rate for both configurations is largely dependent on wind direction, which is also observed in the experimental investigation.

The results for four different configurations of ventilators in different ventilation rates and different airflow and temperatures patterns is investigated by T. Bartzanas et al. (Bartzanas, Boulard, \& Kittas, 2004). The presented results indicate that the highest ventilation rates are not always the best criterion for evaluating the performance to the agriculture crops in the greenhouses. The standard $\mathrm{K}-\epsilon$ model remains the standard model used in the modeling of agricultural structures and applications.

J. Flores-Velazquez et al. (J. Flores, Montero, Baeza, \& Lopez, 2014) used CFD with a standard K- $\epsilon$ model to study more than one aspect, the rate of air change with different ventilation opening in the roof, air speed, humidity and temperature distribution. The temperature measurements inside the greenhouse with three sensors for the greenhouse area $7.5 * 28 \mathrm{~m}$. This area is large to monitor the change in temperature, which is observed in the theoretical study that there is a temperature difference of almost $15 \mathrm{k}$ and these difference could not predict in the experimental measurements, due to the limitation of temperature measuring instruments. Increasing the speed of mechanical ventilation not recommended because it may lead to loss of crops. 
Previous studies have studied the natural and mechanical ventilation in terms of different air speeds, air change rates, roof and side walls openings, but did not sufficiently studied the temperature distribution in experimental and numerical investigations, which is the direct effect on plants and crops in the greenhouse. In previous works computational fluid dynamics (CFD) is used in mechanical and free ventilation of the greenhouses, found some time gaps in the literature CDF studies due to low computational capability of the CFD programs and the limited computing power available at that time. Especially, they failed to describe in detail the effects of fluctuating turbulent airflow and the temperature distribution on the air exchange of the greenhouses with their CFD model.

The objectives of the present study are to verify three-dimensional CFD numerical simulations for different turbulence models (Standard K- $\varepsilon$, RNG K- $\varepsilon$, Reynolds Stress Model (RSM), Transition Shear-Stress Transport (SST), Standard K- $\omega$ and K-KL- $\omega$ ) with air temperature distributions along the greenhouse axis and to compare experimental temperature measurements in a full-scale, mechanical ventilated, even-span greenhouse. Verification tests are during summer day for hot and clear sky.

\section{Experimental Setup}

The experiments located at October 6 University, Giza, Egypt (longitude angle of $29.98^{\circ}$ and latitude angle of $30.95^{\circ}$ ). The measurements are conducted during peak sunshine hours between 10:00 AM and 5:00 PM. The greenhouse has inclined roof type even span greenhouse. The frame is made of rectangular iron pipes and Polycarbonate sheets covering material. The greenhouse with an effective floor $3.6 \times 2.4 \mathrm{~m}^{2}$ with central height $2.4 \mathrm{~m}$ and side walls height $1.8 \mathrm{~m}$ as shown in figure 1 .

A fan of $350 \mathrm{~mm}$ sweep diameter and $1360 \mathrm{rpm}$ with a rated air volume flow rate of 3200 $\mathrm{m}^{3} / \mathrm{h}$ is provided on the south wall of the greenhouse for the forced convection experiments.

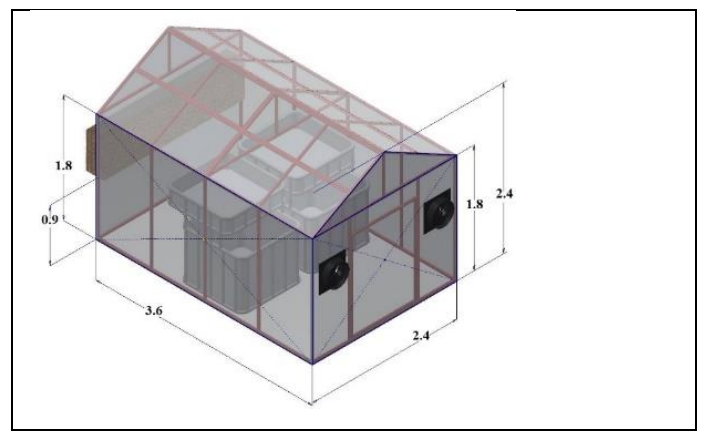

Figure 1 Schematic diagram of the greenhouse (dimensions are in $\mathrm{m}$ ).

Temperature measurement is the most important parameter in the greenhouse. Therefore, good distribution of the position of the temperature measurement sensors is necessary to study the temperature variation inside the greenhouse. 


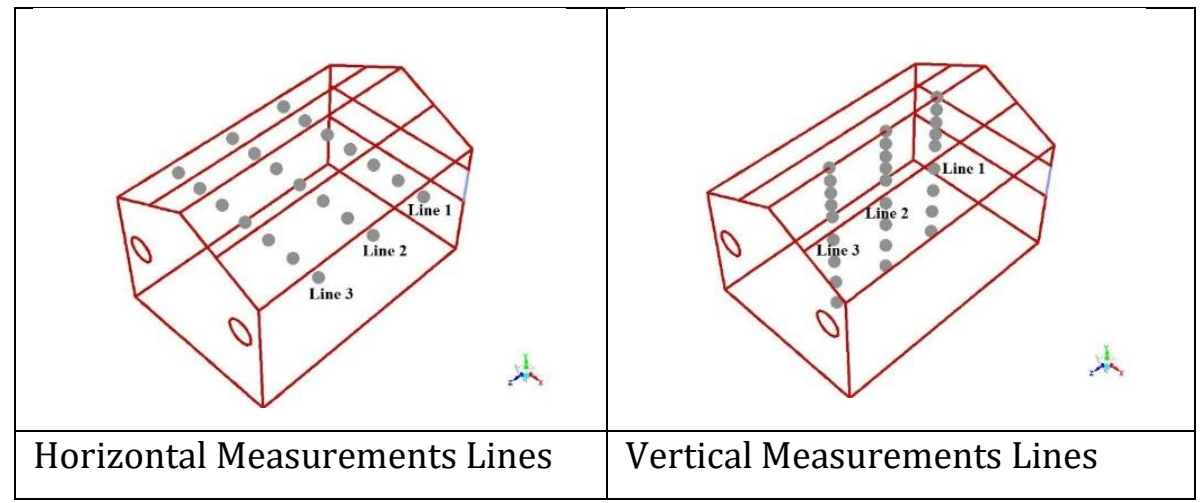

Figure 2 Horizontal and vertical measurements lines.

The temperature sensors are installed in vertical and horizontal lines as shown in figure 2. The positions are $1.6 \mathrm{~m}$ and $1.2 \mathrm{~m}$ for the horizontal and vertical lines respectively. The vertical and horizontal lines distributed inside the greenhouse in three positions; the first quarter, middle and third quarter sections.

Greenhouse walls temperature measured by 7 (DS18B20) temperature sensor one for each wall and two for the even span roof. In each horizontal line locate seven temperature sensors $0.4 \mathrm{~m}$ apart and for the vertical line 9 temperature sensors distributed in two parts, five sensors are used for the bottom part the distance between each of them is $0.4 \mathrm{~m}$, and the top part consists of 4 sensors with $0.2 \mathrm{~m}$ apart. Two temperature sensors are used to measure outside and inside temperature.

\section{Mathematical modelling}

The three-dimensional model of greenhouse structure is established in this study. The cooling pads shape in the ventilation opening and the internal support structure have a small effect on the internal greenhouse temperature, so they are ignored in simplification processing. The ventilation opening placed on the northern wall to reach the maximum cooling effect using the minimum ventilation. The temperature environments for simulation calculation are in hot summer with no wind. Forced ventilation is performed by fan for greenhouses cooling. Entire greenhouse model is divided into 2 million elements. The grid test results show good grid quality. Iterative calculation is conducted using two CPU $3.07 \mathrm{GHz}$ quad-core workstation in simulation.

The governing equations of fluid flow and heat transfer can considered as mathematical formulations of the conservation laws that govern all associated phenomena. These conservation laws describe the rate of change of a desired fluid property as a function of external forces and can written as:

Continuity equation: the mass flows entering a fluid element must balance exactly with those leaving. 


$$
\frac{\partial \rho}{\partial t}+\nabla \cdot[\rho \vec{v}]=S_{m}
$$

Where $\boldsymbol{\rho}$ is the air density, $\mathrm{t}$ is the time, $\overrightarrow{\mathbf{v}}$ is the velocity vector and $\mathbf{S}_{\mathbf{m}}$ is the source term.

Conservation of momentum (Newton's second law): the sum of the external forces acting on the fluid particle is equal to its rate of change of linear momentum.

$$
\frac{\partial}{\partial t}(\rho \overrightarrow{\mathbf{v}})+\nabla \cdot(\rho \overrightarrow{\mathbf{V}} \overrightarrow{\mathbf{V}})=-\nabla p+\rho \overrightarrow{\mathbf{g}}+\overrightarrow{\mathbf{F}}
$$

Where $\mathbf{p}$ is the static pressure and $\overrightarrow{\mathbf{g}}$ and $\overrightarrow{\mathbf{F}}$ are the gravitational body force and external body forces respectively.

Conservation of energy (the first law of thermodynamics): the rate of change of energy of a fluid particle is equal to the heat addition and the work done on the particle.

$U_{j} \frac{\partial \mathrm{T}}{\partial \mathrm{x}_{\mathrm{j}}}=\frac{\partial}{\partial \mathrm{x}_{\mathrm{j}}}\left(\alpha \frac{\partial \mathrm{T}}{\partial \mathrm{x}_{\mathrm{j}}}-\overline{\mathrm{u}_{\mathrm{j}} \mathrm{t}}\right)$

The solution method is run to make the control parameter settings of model in the requirement section. The SIMPLE scheme is used in this study in order to make computing convergence faster. Pressure, momentum, turbulent kinetic energy, turbulent dissipation rate, energy and radiation (discrete ordinate) all used secondorder upwind for more accurately calculate, and relaxation factor settings are as shown in Table 1.

Table 1 Relaxation factor settings of the solution method.

\begin{tabular}{|l|l|l|l|l|l|l|l|l|}
\hline $\begin{array}{l}\text { Pressur } \\
\mathrm{e}\end{array}$ & $\begin{array}{l}\text { Densi } \\
\text { ty }\end{array}$ & $\begin{array}{l}\text { Bod } \\
\mathrm{y} \\
\text { Forc } \\
\mathrm{e}\end{array}$ & $\begin{array}{l}\text { Moment } \\
\text { um }\end{array}$ & $\begin{array}{l}\text { Turbulent } \\
\text { Kinetic } \\
\text { Energy }\end{array}$ & $\begin{array}{l}\text { Turbulent } \\
\text { Dissipatio } \\
\text { n Rate }\end{array}$ & $\begin{array}{l}\text { Turbule } \\
\text { nt } \\
\text { Viscosit } \\
\text { y }\end{array}$ & $\begin{array}{l}\text { Energ } \\
\text { y }\end{array}$ & $\begin{array}{l}\text { Discre } \\
\text { te } \\
\text { Ordina } \\
\text { te }\end{array}$ \\
\hline 0.4 & 1 & 1 & 0.7 & 0.8 & 0.8 & 0.9 & 0.9 & 0.9 \\
\hline
\end{tabular}

The starting point for all problems is a "geometry." Geometries can created using the ANSYS (C17.1 DESIGN MODULER pre-processor software, which is used to create the grid.

A good quality mesh verifies the fast and accurate solution. Therefore, more than one mesh type is tested and compared with each other to attain a good computational fluid dynamics solution. The different mesh methods are multi-zone, automatic, tetrahedral patch conforming and tetrahedral patch independent. Mesh quality depending on more than one parameter; the important two parameters is meshed elements and maximum mesh skewness ratio to ensure that: 
The mesh density should be high enough to capture all relevant flow features.

The mesh adjacent to the wall should be fine enough to resolve the boundary layer flow.

The best method for the greenhouse geometry is tetrahedral patch independent with 4.4 million elements with maximum skewness 0.599 which falls into the "good" range, according to the software standard.

The inlet air conditions are taken as the experiment conditions $33.25^{\circ} \mathrm{C}$. The inlet is set as velocity inlet conditions with velocity inlet $0.25 \mathrm{~m} / \mathrm{s}$ and the turbulence intensity could be assumed to be $5 \%$, and the hydraulic diameter is assumed to be $0.8949 \mathrm{~m}$.

The air outlets are set as pressure outlet conditions. Pressure outlet boundary conditions are used to define the static pressure at flow outlets (and also other scalar variables, in the case of backflow). The temperature of outlet air is $40^{\circ} \mathrm{C}$, and the turbulence intensity could be assumed to be $5 \%$, and the hydraulic diameter is assumed to be $0.35 \mathrm{~m}$.

The greenhouse roof and walls in the model are $0.006 \mathrm{~m}$ thickness double layer polycarbonate glazing material and adding in ANSYS the material properties, it is properties is $1210 \mathrm{~kg} / \mathrm{m}^{3}$ density, $1200 \mathrm{~J} / \mathrm{kg}-\mathrm{k}$ specific heat and $0.21 \mathrm{w} / \mathrm{m}-\mathrm{k}$ thermal conductivity. The walls temperature condition shown in table 4-4 as the experimental measurements.

Table 2 Greenhouse walls temperature measured at 12:00 pm for case 2 .

\begin{tabular}{|l|l|}
\hline Wall & Temperature $\left({ }^{\circ} \mathrm{C}\right)$ \\
\hline Right roof temperature & 42.75 \\
\hline left roof temperature & 41.75 \\
\hline Floor temperature & 33.75 \\
\hline Front wall temperature & 45.75 \\
\hline Right wall temperature & 41 \\
\hline Back wall temperature & 45.75 \\
\hline Left wall temperature & 36.75 \\
\hline Outside temperature & 42.75 \\
\hline
\end{tabular}

\section{Results and discussion}

The working of the greenhouse started at 9 am on the day of the 25 August to ensure that the best representation of the mechanical ventilation inside the greenhouse kept at the peak time in the experimental measurements. The location of the greenhouse (latitude and longitude) and the experiment time introduced in the CFD program to show the radiation effect inside the greenhouse theoretically. 
One of the most important applications of this study is to investigate the best turbulence model can use through CFD to control the temperature distribution inside the greenhouse.

The first three models (Standard K- $\varepsilon$, RNG K- $\varepsilon$ and Reynolds Stress Model (RSM)) compared with the experimental work as shown in figure 3 . The second three models (Transition Shear-Stress Transport (SST), Standard K- $\omega$ and K-KL- $\omega$ ) compared with the experimental work as shown in figure 4.

The Reynolds Stress Model (RSM) seems to have the nearest results comparing which the experimental results. In horizontal line 1, the average temperature difference between the experimental measurements and numerical calculations is about $9 \%$. The largest temperature difference percent is $18.6 \%$ in the middle of the horizontal line. The least difference is $0.7 \%$ on the west wall.

For the vertical line 1 in figure 3, the RNG K- $\varepsilon$ has the nearest results comparing to the experimental measurements. The temperature difference percent in the range of $0.9 \%$ to $19 \%$ with an average value of $10.6 \%$.

The percentage difference value calculated as:

$$
\% \text { value }=\frac{t_{\text {num }}-t_{\text {exp }}}{t_{\text {exp }}} \times 100
$$

Where:

$t_{\text {num }}$ : the numerical temperature results

$t_{\text {exp }}:$ the experimental temperature measurements

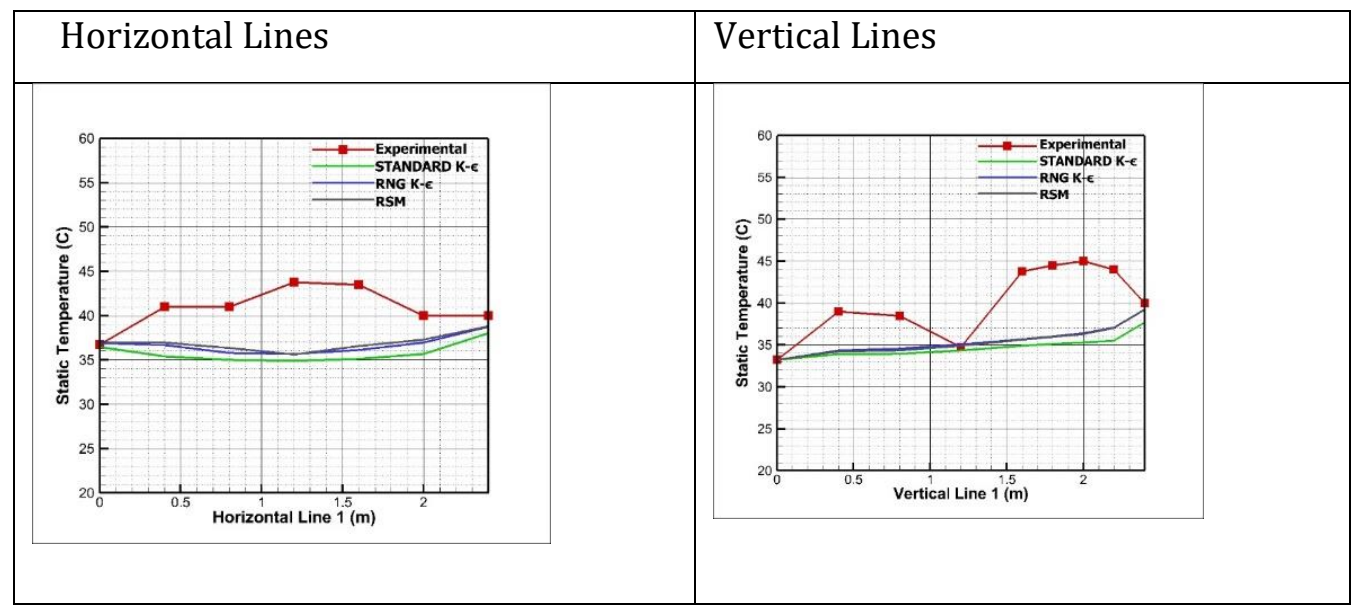



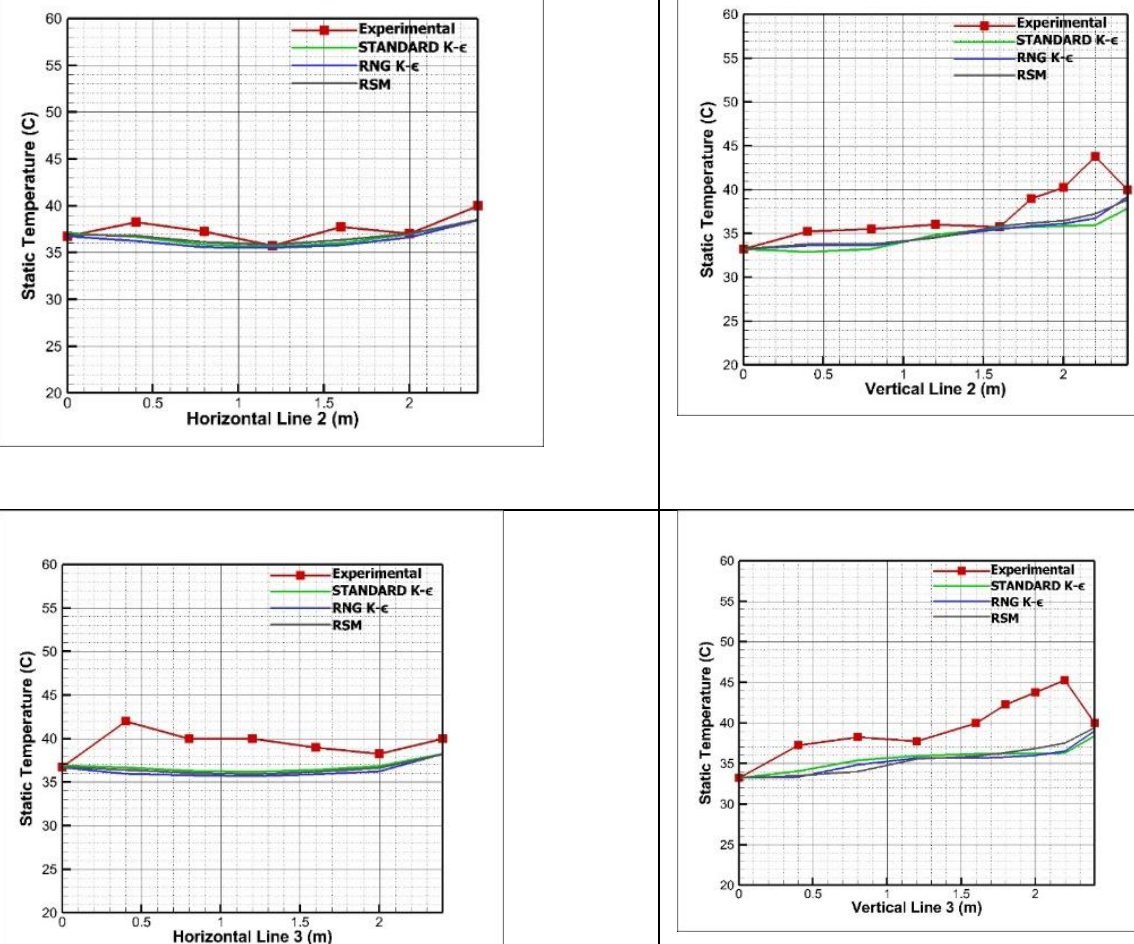

Figure 3 Experimental and numerical comparison for temperature variation at horizontal and vertical lines.

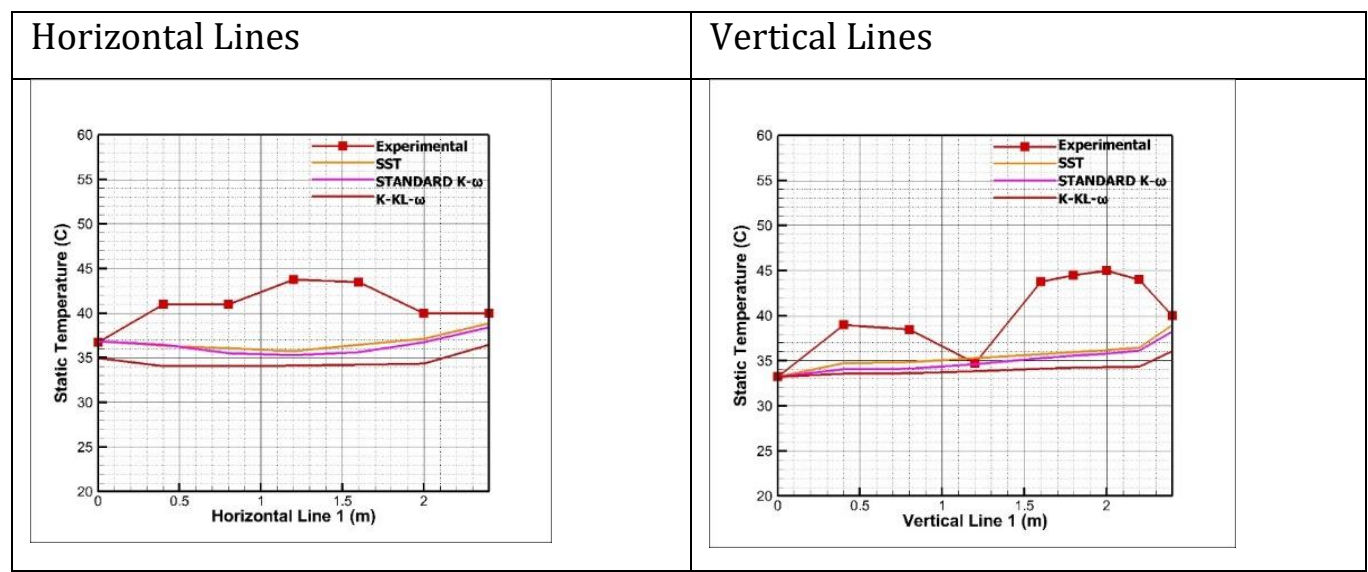




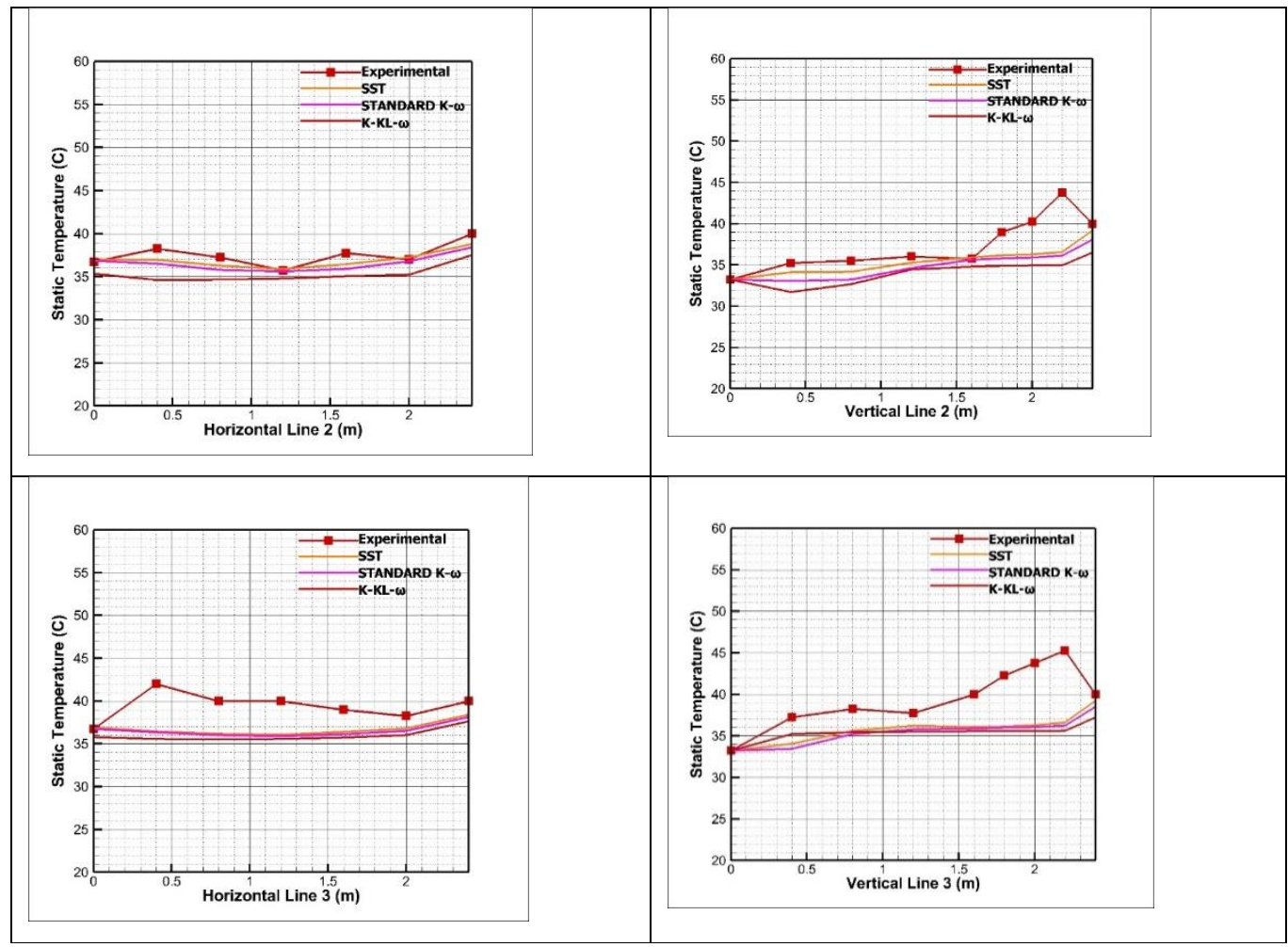

Figure 4 Experimental and numerical comparison for temperature variation at horizontal and vertical lines.

The highest temperature difference found at height $2 \mathrm{~m}$ in the triangle zone under the even span roof. This increase is due to the effect of the greenhouse effect at the top of the greenhouse. Therefore, there is always a discrepancy between the experimental measurements and the numerical calculations in this region. The temperature difference between the experimental measurements and numerical solution is about zero at the points $0 \mathrm{~m}, 1.2 \mathrm{~m}$, and $2.4 \mathrm{~m}$.

In horizontal line 2 , it can notice that small average temperature difference between the experimental measurements and numerical calculations especially for SST model as shown in figure 4 , the average percentage difference is $1.48 \%$. The largest temperature difference is $3.39 \%$, and the minimum is $0.75 \%$.

For the vertical line 2 the lowest temperature difference between the experimental measurements and numerical calculations for SST model as shown in figure 4, the average temperature difference is $4.85 \%$, where the least and the greatest values are $0.49 \%$ and $16.38 \%$ respectively. 
As shown in figure 3 in the third horizontal line, the nearest solution to the experimental results applying the standard $\mathrm{K}-\varepsilon$ model. The average temperature difference is $6.5 \%$ where the least temperature difference is $0.45 \%$, and the maximum is $12.6 \%$.

SST model is the nearest solution for the third vertical line. The average temperature difference is $9 \%$ for the highest value of the temperature difference which is $19 \%$, and the lowest value is $1.9 \%$.

The effect of the sun's movement between east and west shown in the horizontal lines in figure 3 and 4 . There is a temperature difference between the east and west sides is $3.25^{\circ} \mathrm{C}$ in the experimental measurements. The corresponding value for the numerical study is $1.4^{\circ} \mathrm{C}$.

Also saw on the vertical lines in figure 3 and 4 the temperature difference is raised from the surface of the ground and the greatest height of the greenhouse and significantly the greenhouse effect, especially from the height of $1.5 \mathrm{~m}$ to the highest level of the greenhouse.

Comparison between all models, the results are shown in figure 5, one can conclude that the most efficient turbulence models in the SST model.

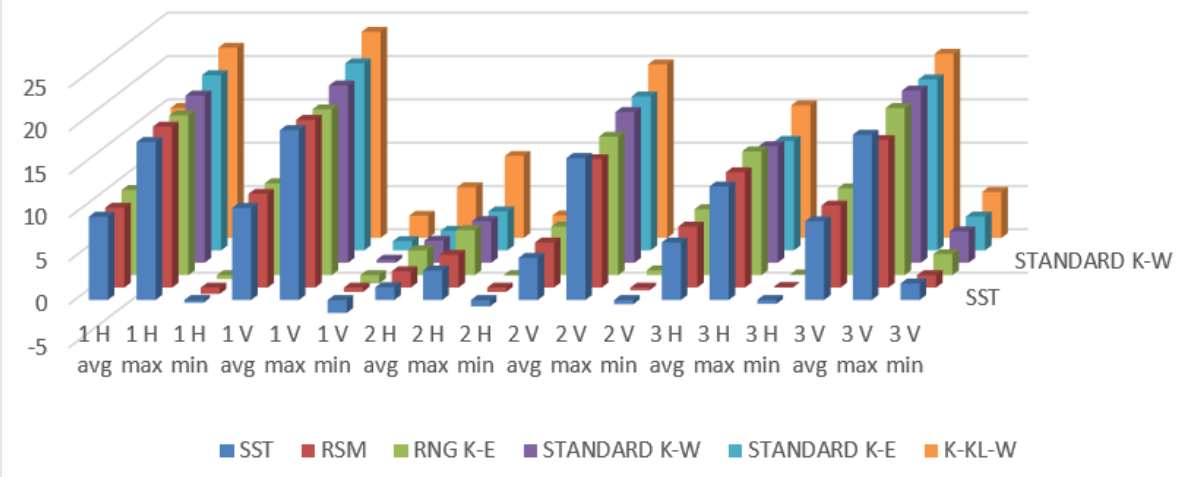

Figure 5 Percentage temperature difference between the experimental measurements and different turbulence models.

\section{Conclusion}

The influence of mechanical ventilation of an even-span greenhouse is numerically investigated using commercial fluid dynamics code. A good qualitative and quantitative agreement is found between the numerical results and the experimental measurements.

Must check different turbulence modules to find the suitable one, so six turbulence models applied in the present theoretical study: Standard K- $\varepsilon$, RNG K- $\varepsilon$, Reynolds Stress Model (RSM) and Transition Shear-Stress Transport (SST), Standard K- $\omega$ and K-KL- $\omega$. 
The effect of mechanical ventilation of an even-span greenhouse numerically investigated using commercial fluid dynamics code. A good qualitative and quantitative agreement found between the numerical results and the experimental measurements. The deviation between the two results was about $8 \%$ for all traversed lines.

The more efficient turbulence model in the present study is the SST model which gives nearly approaching results with the experimental measurements.

A good agreement between experimental measurements and numerical calculations, it can rely more on theoretical solutions.

\section{References}

[1] L. Okushima, S. Sase and M. Nara, "A support system for natural ventilation design of greenhouses based on computational aerodynamics," Acta Horticulturae, vol. 284, p. 129-136, 1989.

[2] S. Sase and T. Takakura, "Wind tunnel testing on airflow and temperature distribution of a naturally ventilated greenhouse," Acta Horticulturae , vol. 148, p. 329-336, 1984.

[3] I. B. Lee and T. H. Short, "Verification of Computational Fluid Dynamic Temperature Simulations in A Full-Scale Naturally Ventilated Greenhouse," Transactions of the ASAE, vol. 44, no. 1, p. 119-127, 2000.

[4] J. B. Campen and G. P. A. Bot, "Determination of Greenhouse-specific Aspects of Ventilation using Three-dimensional Computational Fluid Dynamics," Biosystems Engineering, vol. 84 , no. 1, p. 69-77, 2003.

[5] T. Bartzanas, T. Boulard and C. Kittas, "Effect of vent arrangement on windward ventilation of a tunnel greenhouse," Biosystems Engineering, vol. 88, p. 479-490, 2004.

[6] V. J. Flores, J. I. Montero, E. J. Baeza and J. Lopez, "Mechanical and natural ventilation systems in a greenhouse designed using computational fluid dynamics," Int J Agric \& Biol Eng, vol. 7, no. 1, p. 1-16, 2014. 